\title{
Adolescences' Perspectives of Dealing with Syria Traumatic Events
}

\author{
Tatiana Pilishvili* \\ Al' Massri Ismaeel \\ Natalya Karabushchenko \\ Alexandr Ivashchenko \\ Peoples' Friendship University of Russia, *Address correspondence to this author, Associate professor \\ The Department of Philology, Psychology and Pedagogic Chair, Peoples' Friendship \\ University of Russia, Moscow, Russia; pilishvili_ts@pfur.ru
}

\section{Doi:10.5901/mjss.2016.v7n3s1p238}

\section{Abstract}

This study aimed to explore how adolescences, who have experienced the Syrian War traumatic events, choose their ways of coping and deal with the secondary trauma out of their native country (150 participants, 75 male, 75 female; 15-17 years old, average age 16 years). It's clear in this study the reflection of the psychosomatic state specifics developed at the background of the harmful psycho events of psychological adaptation to a new situation which consists of the compelled migration from Syria to Jordan and staying in a refugee camp. Developed possibilities of adaptation resources of the personality in the context of a proactive coping with a crisis situation in connection with possible post-traumatic growth are shown. Unproductive and productive factors of adaptation of Syrian youth are revealed. The unproductive factors are: a) the factor of the expressed repeated traumatic experiences which are followed by problems with a dream, the increased irritability, fits of anger, loss of sense of reality; b) the factor of anxiety - personality's uncertainty in his or her own forces and subjective inability to control itself and the environment; c) the disadaptive factor with emotional difficulties, uncertainty, avoiding communicating with the contemporaries to deal with the problem. The productive factors of adaptation are: a) the factor of strategic planning, the search of adaption to find a way from a stressful situation by means of additional information, councils, division of feelings with others; b) the factor of own experience reconsideration for the purpose of adaptation to new vital conditions.

Keywords: Syrian war, refugees, PTSD, adaptation, posttraumatic growth, proactive coping.

\section{Introduction}

The extreme situation of sociogenic character is essentially different because of somebody's presence in it as an aggressor that inevitably creates difficulties of adaptation to a new reality where there are, in the quality of challenges, not only social and economic consequences of military operations in the homeland, but also a search of kindness in the human nature. It is noted that PTSD or any other event of absolutely other character connected with that "contrary to a trauma background the growth is not only sudden according to its interesting essence, but is also directed on the multilateral program of human coping and adaptation" (Magomed-Jeminov, 2009, p. 112), it may be a cause or as a result of an extreme situation however. This phenomenon is designated in modern psychological literature as "the posttraumatic growth" (Magomed-Jeminov, Kvasova, Savina, 2015; Johnson, Boals, 2015; Parslow, Jorm, 2007; Salah, Qureshi, Long, 2011) and it also means a possibility of the transformation quality of the personality regarding its development and transition to the new level of adaptation.

Psychological adaptation to new living conditions represents a difficult multilevel process demanding activation of essential mental efforts of the personality and endured as a rather stressful situation. In the conditions of the compelled migration escaping from the war in the homeland to other state adaptation objectively becomes a psycho injuring situation that considerably affects the nature of how to overcome it. It is noted that "in each mental adaptation case gets emotional colouring and dynamics according to features of mental characteristics of the individual that is shown in his mental state" (Magomed-Jeminov., Kvasova., Savina, 2015, p. 29). Thus the connection between "social and psychological adaptation of the personality and coping-behavioral strategy" is revealed (Malyshev, 2012 . p. 18). 


\section{Literature Review}

The details of modern psychological researches of personality coping with a stress consists of allocation by a number of authors (L. Aspinwall, Sh. Taylor, E. Greenglass, R. Schwarzer, L. Fiksenbaum, etc.) along with a traditional (reactive) coping of a so-called proactive coping (Pilishvili, 2014). The latter is essentially different from the reactive reaction because it can come before the stressful event. Active overcoming assumes orientation to the future generation of personal resources for the search of the best decision, and also emotional self-control. R. Schwarzer notes that at a reactive coping the personality operates risks as he estimates the stressful event from the point of threats, losses, harm (Schwarzer, 2000). The active overcoming focuses personal efforts at the management of the purposes as the future stressful event which is perceived here rather as the challenge demanding the answer. In this regard, the motivation of the proactive coping becomes positive, unlike the reactive coping, motivated by negative incentive-threat. It is emphasized that preliminary accumulation of overcoming resources "acts as a "buffer" at facing difficult or stress situations" (Vodop'janova, Starchenkova, 2009, p. 22). Thus the importance of the personality already acts in a difficult life situation as a resource of the process of overcoming (Kochkareva, 2009).

A number of authors marks out, that even in a situation of an objective psychotrauma, it is possible to overcome it positively and achieve satisfaction with life as a result (Israel-Cohen, Uzefovsky, Kashy-Rosenbaum, Kaplan, 2015). Nowadays subjective wellbeing of the personality becomes not only an independent problem of a separately taken person, but a universal call as in case of psychotrauma situation, especially divided by representatives of the whole states, a threat of the "growth of the aggression having a protective character" (Pilishvili, Al' Massri Ismeel, 2013, p. 50) becomes potential. It is shown that the strategy of the correction of aggression is connected with efficiency of self-control as the highest level of personality's activity (Tarasova, 2010).

Personality's activity carries out the following functions in the course of an activity: 1) adaption, consisting of adequate estimation and the individual's adaptation to constantly changing environment conditions; 2) transformative, i.e. beyond actually adaptive function, including upper-situational activity; 3 ) the overcoming function consisting in a proactive coping at an assessment of potential difficulties not as threats, but in the form of the challenges demanding the answer; 4) the function of interaction of the subject with the world around it - the subject relations act as a basis for formation of resource conditions of the personality; $b$ ) the function of self-development of the personality which is based on selfdetermination, continuation of in space and time of life.

It is possible to allocate very provisionally two ways of personality's formation of a life course, on the one hand, "through mastering own time of life structure, on the other hand, through self-organization of event layer of life" (Pilishvili, 2014, p. 7). In our opinion, the active coping as an element of an estimated and behavioral component of activity of the personality (Medvedskaya, 2010) allows: a) to become the subject of own life in indissoluble connection of the pastpresent-future by management of the purposes and prospects of development of a potential stressful situation; $b$ ) to provide resonant to an internal positive state of the life course by means of management of intra personal, social, environmental resources. Concerning the overcoming of the psycho injuring situation by adolescences and high school students, it is shown that in the conditions of a stress the probability of deviant behavior and the use of psychoactive agents significantly increase (Goldstein et al., 2011).

In a hypothesis of the conducted research we assumed that there is a connection between the use of a proactive coping as the personality's resource potential and effective adaptation to new environmental parameters "as a process of the active adaptation of the individual to conditions of the social environment mentioning all levels of functioning of the person" (Krupnov, Sheptura, 2014, p. 66). Experiences of age crisis are imposed in a case of reaction with the Syrian young men and girls to an extreme situation (the military conflict in the homeland, the compelled migration). Thus negative mental states, normal for a stress, are aggravated with a grief of loss of relatives, and also serious psychological consequences of the compelled stay in the refugee. However, even in similar conditions the personality has some resources for adaptation to new conditions of the environment. The objective of this research was to study the features of adaptation to an extreme sociogenic situation among the Syrian high school students by the example of staying in the refugee as a result of the military conflict in the homeland. In particular, we assumed that there are peculiarities of adaptation among the Syrian adolescences to an extreme situation of sociogenic character in connection with an actual psychosomatic state, and also with a character of personality's stress overcoming. 


\section{Method}

\subsection{Participants}

The participants were 150 Syrian adolescences ( 75 male and 75 female), all of whom had been resided as refugees in the northern part of Jordan at "Al-Zaatari" refugee camp from June 2013 to May 2014 as a result of military operations on the territory of Damascus, Daraa and Homs. The average age of the participants was 15.94 years (SD=0.58). Among them, 62 adolescences survived the sudden death of a relative, all of the participants were affected by various bodily ailments in the gastrointestinal tract, respiratory system, cardiovascular system, headaches, nervous trembling.

\subsection{Materials}

1. The Proactive Coping Inventory (PCl; Greenglass, Schwarzer, Taubert, 1999) was developed and standardized on several samples. The PCI was translated to Arab by Gaber Mohamed Abdallah \& Greenglass E. (Gaber Mohamed Abdallah, Greenglass, 2008). The original measure was designed to assess 7 scales: proactive coping, reflective coping, strategic planning, preventive coping, instrumental support seeking, emotional support seeking, avoidance coping. Respondents are presented with four alternatives: "not at all true", "barely true", "somewhat true", "completely true." Scoring: 1 is assigned to "not at all true, 2 to "barely true", 3 to "somewhat true" and 4 to "completely true". We used it the PCI to see the influence of coping factors on death anxiety and PTSD among participants.

2. The Essener Trauma-Inventar for adolescences (ETI-KJ) was created by S. Tagay, Düllmann S, Hermans E, Repic N, Hiller R, Senf W. for detection of psycho-traumatic events and post-traumatic stress disorders, considering criterions of diagnosing according to DSM-IV (Tagay et al., 2011). The questionnaire consists of 5 parts (Tagay et al., 2009).

The first part includes the list of injuries with 14 possible events. The examinee answers a question, whether he has endured certain potentially traumatic event personally or as an observer. In the second part the chronology of the psycho injuring event is specified which is characterized according to DSM-IV by the criterion of A1 (threat of physical integrity); A2 (subjective estimate of fear, horror or helplessness). The third part includes 23 points concerning actual post-traumatic symptomatology. Rate of manifestation is measured on a four-stage scale of Laykert with values: 0 - "absolutely not", 1 - is "rare", 2 - is "frequent" and 3 - "it is very frequent". These values are applicable for PTSD on three simptomny clusters: intrusion (V-criterion), avoiding (S-criterion), hypererethism (D-criterion).

In the fourth part there is a questionnaire of the criterions of a stressor taken from DSM-IV which allows to carry out screening concerning the available PTSD or ASD to combinations with the established values.If both criterions of a stressor (A1 \& A2) are executed and the sum of values in the sections of repeated experience of an event, avoiding and hypererethism reaches 27 points and above, it testifies PTSD existence. Value from 0 to 15 can be characterized as insignificant. Values from 16 to 26 are boundary and speak about partial PTSD. ETI-KJ also diagnostsi dissociative symptomatology (at ASD V-criterion). The instruction on the available ASD is the general minimum meaning 35 received from sections of the Intrusion, Avoiding, Hypererethism and Dissociation. In addition to symptomatic clusters of PTSD and ASD each subsequent point covers somatic complaints which for the first time appeared after the psychoinjuring event. Also there are 2 questions on chronology of symptoms (E-criterion). Further on a six-step scale of Laykert it is estimated how burdening is the occurred event at the moment. The fifth part includes 6 points which cover symptomatic caused restrictions in everyday life (F-criterion)

3. The reference to the OSR existing is the general minimum value 35 received from the "Methods of measurement of adolescent anxiety" by U. A. Zaytseva is intended for teenagers for senior teenage and early youthful age (Baitinger, 1998, p. 42-50). Activies significant for senior teenage and early youthful age were the source for allocation of scales and points of the questionnaire: scale of the interpersonal relationship with contemporaries; scale of relationship with parents; scale anxiety concerning the future; scale of self-estimated anxiety. At the creation of the questions directed on the detection of a teenage anxiety, authors of the technique leaned on determination of anxiety as personality's tendencies to consider many situations as menacing ,thus meaning not so much physical threat, but a social component, own representation about "future Me".

4. Krupnov's "Adaptability" questionnaire (Krupnov, 2007) consists of 6 blocks, each of which comprises a 
complete description of one of the adaptability components: communicative difficulties, difficulties in confidence, emotional difficulties, nostalgia, estrangement, adaptation. Each block consists of 10 statements made according to the signs opening adaptability as a personality trait. The test includes 60 statements, to each of which a respondent expresses the relation, choosing the answer from seven possible options (1 - "not at all"; 2 - "no"; 3 - "perhaps, no"; 4 - "something in the middle of"; 5 - "perhaps, yes"; 6 - "yes"; 7 "undoubtedly yes").

The above-mentioned questionnaires were used because they meet the validity requirements. They are adequate to purpose, hypothesis and research subject. The measurement scales used in the study needed to be in an Arab version since the subjects were all monolingual (speaking Arabic). For the first two techniques, the available options of questionnaires adapted on the Arab selection were taken. For two last questionnaires there were used double translate technic. First, a bilingual, Arab-speaking psychologist translated the scales from Russian to Arab. The Arab scales were then compared to the Russian versions by another bilingual psychologist, and any differences in the items were discussed and resolved before they were included in the final Arab questionnaire.

\subsection{Procedure}

The study was conducted by the second author for 12 months from June 2013 to May 2014 in northern Jordan at "AlZaatari" refugee camp among adolescences. Most of the refugees were from the Governorates of southern Syria, Damascus, Daraa and Homs. Potential participants were given detailed information sheets and were asked to send back an "opt-in" form should they wish to take part. The research was described fully, and the participants asked any question they wished in order to gain informed consent. The main difficulties which we faced were the organization of people for carrying out research. It was important for us to establish confidential contact at which the essential part of time was spent to explain that it was for scientific needs to study the problem of PTSD by adolescences. Difficulties with return of "opt-in" forms were also observed. From more than 250 information sheets distributed by us it was returned only 150 . We connect it with difficulties of own state understanding which find deep personal problems of adolescences. The questions connected with the death of relatives, anxiety about the future, sexual sphere cause complex feelings in participants. However, as a whole, considering a traumatic condition of participants, it's possible to say that they treated the work of the psychologist with understanding and respect. For processing of the obtained data by PFUR scientists Mann Whitney U-test, Spearman's rank correlation and factorial analysis were used.

\section{Results}

\subsection{Descriptive statistics}

The descriptive statistics shows that $42 \%$ of examinees endure a grief of loss of a close person or a family member, $100 \%$ of the selection show dissociation symptoms; $98 \%$ of examinees have hypererethism symptoms; $100 \%$ of respondents show symptoms of avoiding and endure the intrusion; $98 \%$ of examinees consider subjectively the situation as terrible, awful, endure helplessness; $95 \%$ of examinees within the current situation in the homeland at least once experienced threat of physical integrity; $94 \%$ of respondents have become the witness of a traumatic event; $93 \%$ of examinees personally have endured a traumatic event; $96 \%$ suffer from a number of psychosomatic diseases that matches with the results of early PTSD researches (Koo et al., 2016).

Young men and girls of the studied selection experience different types of corporal indispositions; $37 \%$ of the young men and $24 \%$ of the girls have disorders of a digestive tract; $36 \%$ of the young men and $36 \%$ of the girls have frustration of respiratory system; $32 \%$ of the young men and $27 \%$ of the girls have cardiovascular problems; $57 \%$ of the young men and $56 \%$ of the girls have a nervous tremor; $67 \%$ of the young men and $81 \%$ of the girls feel a headache. The studied selection differs in the increased level of anxiety; it isn't revealed any examinee with a low level of anxiety. The examinees endure the highest level of anxiety concerning the future (94\%) and also anxiety concerning the relations with contemporaries (74\%). The adaptation profile among the young men and the girls in general is similar, it is obviously different in scales of uncertainty and emotional difficulties with higher values among the girls of the studied selection in comparison with the young men. The most widespread productive coping strategy in this selection of the Syrian teenagers is the search of emotional support (41\%), reflexive overcoming of crisis (32\%), search of tool support (26\%), strategic planning (19\%). 


\subsection{Comparative analysis results}

For the purpose of detection of distinctions in the features of adaptation to new living conditions by A.I. Krupnov's technique among the teenagers having various somatic symptoms, the Mann - Whitney U-test was applied. It is revealed that there are statistically significant distinctions on a scale of communicative difficulties for young men in connection with existence and lack of gastrointestinal frustration $(U=0.042 ; p=0.01 ; M 1=80.28 ; M 2=64.68)$. It is also revealed that there are statically significant distinctions on an uncertainty scale for the young men with difficulties of respiratory system in comparison with the young men who haven't declared indispositions in this area $(U=0.037 ; p=0.01$; $M 1=69.94 ; M 2=85.37$ ). It was revealed that there are statistically significant distinctions on an uncertainty scale for the young men with existence and lack of a nervous tremor $(U=0.011 ; p=0.01 ; M 1=30.57 ; M 2=43.52)$. Distinctions on a nostalgia scale among the young men with headaches and without those are revealed $(U=0.033 ; p=0.01 ; M 1=45.54$; $\mathrm{M} 2=34.23)$. Results of the Mann - Whitney U-test among the girls show that there are statistically significant distinctions in adaptation level among the high school students with the high and average level of anxiety $(U=0.045 ; p=0.01$; $\mathrm{M} 1=46.21 ; \mathrm{M} 2=35.59)$.

\subsection{Correlation analysis results}

The following significant correlations according to the ETI-KJ test and scales of other questionnaires are revealed. There are positive correlations between personally endured psychoinjuring event and the intrusion (Rs=0.48; $p=.005$ ); PTSD (Rs=0.44; $p=0.005$ ); avoiding (Rs=0.28; $p=0.005$ ); dissociation (Rs=0.26; $p=0.005$ ); deterioration of the psychosocial relations (Rs $=0.20 ; p=0.005$ ); threat of physical integrity ( $R s=0.18 ; p=0.005$ ); subjective estimation of fear, helplessness (Rs=0.18; $p=0.005)$; search of instruments of social support (Rs=0.17; $p=0.005)$. Positive correlations between experience of the potentially traumatic event as an observer and the intrusion are revealed (Rs=0.28; $p=.005$ ); deterioration of the psychosocial relations ( $R s=0.27 ; p=$. 005); dissociation ( $R s=0.20 ; p=0.005)$; PTSD (Rs $=0.20$; $p=0.005)$; reflective coping ( $R s=0.18 ; p=0.005)$; avoiding ( $R s=0.18 ; p=0.005)$; adaptation ( $R s=0.16 ; p=0.005)$. Positive correlations between threat of physical integrity and PTSD are revealed (Rs $=0.26 ; p=0.005$ ); deterioration of the psychosocial relations (Rs=0.26; $p=0.005$ ); dissociation ( $R s=0.23 ; p=0.005)$; emotional difficulties ( $R s=0.19 ; p=0.005$ ); avoiding (Rs=0.18; $\mathrm{p}=0.005)$.

Positive correlations between subjective estimation of fear, or helplessness and PTSD are revealed $(\mathrm{Rs}=0.36$; $p=0.005$ ); intrusion ( $R s=0.32 ; p=0.005$ ); avoiding ( $R s=0.29 ; p=0.005)$; communicative difficulties (Rs $=0.20 ; p=0.005$ ); uncertainty (Rs=0.23; $p=0.005$ ); anxiety about the future (to $R s=0.20 ; p=0.005$ ); dissociation (Rs=0.20; $p=0.005$ ); emotional difficulties (Rs=0.19; $p=0.005$ ); personally endured psychoinjuring event (Rs=0.18; $p=0.005$ ); strategic planning (Rs=0.17; $p=0.005)$. Positive correlations between the intrusion and dissociation are revealed( $R s=0.60 ; p=0.005) ; P T S D$ (Rs=0.50; $p=0.005$ ); personally endured psychoinjuring event (Rs=0.48; $p=0.005$ ); avoiding (Rs $=0.46 ; p=0.005$ ); deterioration of the psychosocial relations ( $R s=0.37 ; p=0.005$ ); subjective estimation of fear, helplessness (Rs $=0.32$; $p=0.005$ ); experience of potentially traumatic event as an observer (Rs $=0.28 ; p=0.005$ ); general anxiety (Rs $=0.26$; $p=0.005$ ); anxiety concerning parents (to $R s=0.26 ; p=0.005$ ); search of instruments of social support (Rs $=0.24 ; p=0.005$ ); anxiety about the future (to $R s=0.22 ; p=0.005$ ); threat of physical integrity (Rs $=0.20 ; p=0.005$ ); the avoiding coping (Rs=0.16; $p=0.005$ ); adaptation (Rs=0.16; $p=0.005$ ); emotional difficulties (Rs=0.05; $p=0.005$ ).

Positive correlations between hyperexcitability and avoiding are revealed (Rs $=0.63 ; p=0.005$ ); dissociation (Rs=0.58; $p=0.005$ ); intrusion (Rs=0.50; $p=0.005) ;$ personally endured psychoinjuring event ( $R s=0.44 ; p=0.005)$; subjective estimation of fear, helplessness ( $R s=0.36 ; p=0.005)$; general anxiety $(R s=0.28 ; p=0.005)$; emotional difficulties (Rs=0.26; $p=0.005$ ); threat of physical integrity (Rs $=0.26 ; p=.005$ ); anxiety concerning parents (to Rs $=0.26 ; p=.005$ ); anxiety about the future (to $R s=0.25 ; p=0.005)$; deterioration of the psychosocial relations (Rs=0.24; $p=0.005$ ); anxiety concerning a self-estimated anxiety ( $R s=0.22 ; p=0.005)$; uncertainty ( $R s=0.21 ; p=0.005)$; experience of potentially traumatic event as an observer (Rs=0.20; $p=0.005$ ).

Positive correlations between dissociation and intrusion are revealed (Rs=0.60; $p=0.005$ ); PTSD (Rs $=0.58$; $p=0.005$ ); avoiding (Rs $=0.48 ; p=0.005$ ); deterioration of the psychosocial relations ( $R s=0.40 ; p=0.005$ ); personally endured psychoinjuring event (Rs=0.26; $p=0.005$ ); emotional difficulties ( $R s=0.25 ; p=.005$ ); threat of physical integrity $(R s=0.23 ; p=0.005)$; experience of potentially traumatic event as an observer ( $R s=0.20 ; p=0.005)$; subjective estimation of fear, helplessness (Rs $=0.20 ; p=0.005$ ); general anxiety (Rs $=0.20 ; p=0.005$ ); self anxiety (Rs $=0.20 ; p=0.005$ ); anxiety about the future (to $R s=0.19 ; p=0.005$ ); avoiding coping ( $R s=0.19 ; p=0.005$ ). Positive correlations between deterioration of the psychosocial relations and dissociation are revealed(Rs=0.40; $p=0.005$ ); intrusion ( $R s=0.37 ; p=0.005$ ); avoiding $(R s=0.29 ; p=0.005$ ); experience of potentially traumatic event as an observer ( $R s=0.27 ; p=0.005$ ); threat of physical 
integrity (Rs $=0.26 ; p=0.005$ ); PTSD ( $R s=0.24 ; p=0.005$ ); communicative difficulties ( $R s=0.20 ; p=0.005$ ); personally endured psychoinjuring event (Rs=0.20; $p=0.005)$.

\subsection{Factor analysis results}

By results of the carried-out factorial analysis by means of rotation of Varimax, it is possible to allocate the following factors of adaptation of the Syrian teenagers.

The first factor includes variables: intrusion (0.75); hypexcitability (0.74); dissociation (0.69); personally endured traumatic event (0.65); avoiding (0.59); deterioration of a psychosocial state $(0.52)$; threat of physical integrity $(0.46)$; observed traumatic event (0.41). Variables of personally endured traumatic event, an observed traumatic event, sharp stressful frustration, threat of physical integrity unite in themselves the remained indicators. Thus, this factor is designated as a factor of the expressed repeated traumatic experiences which are followed by problems with a dream, increased irritability, fits of anger, loss of sense of reality. The second factor includes the following variables: preventive coping (0.80); proactive coping (0.75); search of emotional support (0.71) reflective coping (0.69); search of instruments of support (0.60); strategic planning (0.49); adaptation (0.43). This factor unites in itself productive coping focused on the future, and also the process of adaptation and it was designated as a factor of strategic planning, the adaptive and aimed search of an exit from a stressful situation by means of additional information, councils, sharing of feelings with others.

The third factor includes the following variables: general anxiety (0.97); anxiety about the future (0.73); anxiety concerning relations with parents (0.71); anxiety connected with a self-assessment $(0.68)$; anxiety concerning relations with contemporaries (0.61). This factor was designated by us as a factor of anxiety-uncertainty of the personality in own forces and subjective inability to control itself and an environment. The fourth factor includes the following variables: uncertainty (0.73); emotional difficulties (0.59); the avoiding coping (0.53); adaptation (-0.49); anxiety concerning relations with contemporaries (0.44). This factor is designated as a disadaptation factor with emotional difficulties, self-uncertainty, avoiding of communication with contemporaries about a problem. The fifth factor includes the following variables: nostalgia (0.64); alienation (0.63); reflective coping (0.45); adaptation (0.41). This factor is designated as a factor of reconsideration of own experience for the purpose of adaptation to new vital conditions.

\section{Discussion}

It has already become clear at a stage of descriptive statistics that Syrian young men and girls endure unequally from the corporal symptomatology an extreme sociogenic situation of staying in the refuge to escape from the war in the homeland. It is remarkable that in general young men aim mainly to preserve their own negative emotions, their hiding from other people. Apparently, it is connected with their desire to remain strong, to show absence of fear. In this regard it is possible to speak about bigger risk of development of psychosomatic frustration among the young men of the tested selection. The young men, who according to own data don't have digestive tract indispositions, experience stronger communicative difficulties, feeling of misunderstanding from the interlocutor, impatience in communication, feeling of loneliness even among other people. They show painful experience of language barriers in interethnic communication, resistant stereotypes, and also homesickness. It, apparently, means that the strong feeling of fear which is unconsciously transferred to gastrointestinal frustration partially decreases due to deterioration of a somatic condition of the personality. The feeling of uncertainty is followed by difficulty of breath and because of this mutual strengthening of a physiological and psychological state of instability increases. Among the young men with absence of a headache it is observed a stronger desire to return home. They differ in existence of constant memories of the past, family, and also deep feeling of melancholy for the native nature and the house. Perhaps, the headache in this case acts as the compensatory mechanism and, paying to itself additional attention, partially dulls painful memoirs. The somatic condition of tremor among the young men is followed by psychological experience of confusion, doubt, they fall into a panic condition easier while facing with suddenness in a new situation, and they depreciate themselves and their abilities.

We must emphasize that the revealed distinctions are present only among the young men of the studied selection. Thus somatic frustrations have partially compensatory character among the young men or, on the contrary, worsen a psychological condition. Perhaps, it is connected with the increased responsibility, and also a ban on expression of emotions by men, need of their high self-control in Syria as the country of the Arab world. These data in a certain manner match with the results of adaptation manifestation among the Arab adolescents which have been received earlier by us (Pilishvili, Al Massri Ismaeel, 2015). Paradoxically a manifestation of negative and unacceptable within culture emotions becomes possible and even socially desirable in the course of deterioration of a somatic state.

A lower level of adaptation is revealed among the girls with a high level of anxiety as a personal trait. They aren't 
more often able to adapt to a new situation, to overcome difficulties, to anticipate following events. They manage worse communication with people because the passivity and low authorship of life. Thus, the group of risk among the girls is made by those examinees, who insufficiently operate their own anxiety, estimate a situation as unsafe in wider range in comparison with the young men.

Among the examinees of the both sexes PTSD sings have been revealed along with anxiety, in particular anxiety concerning their own future, and also concerning relations with contemporaries. Possibly, it is connected with a fact that the serious negative experiences of a substandard difficult vital event (war on the homeland and the compelled migration) are imposed on the upper bound of a standard age crisis of teenage-youthful age. It increases anxiety in productivity of the leading activity of the examinees, connected with a) communication with contemporaries and b) future selfdetermination. In this case there is a violation by the principle "it tears, where something is thin". According to various forecasts the war in Syria can still last for rather a long time, and on arrival home they are waited by rather serious trials which teenagers owing to the age can't really estimate. Accommodation conditions in the camp are also rather traumatic, and people, who live there, don't usually have elementary safety conditions. Constantly arriving flow of refugees only aggravates the situation, bringing hopeless messages from the homeland. In this regard most of the Syrian teenagers mostly need emotional support of people around and an opportunity to see prospects of further life.

On the other hand, the standard age crisis defines not only above-mentioned risks of PTSD development, but also paradoxically relates with a way to a new level of development of the personality. So, through search of social support the way out from the limits of own experiences and their division with other people can be carried out.

Results of the correlation analysis show that for examinees are available both risks of further development of PTSD, and potential posttraumatic growth. So, at numerous correlations within PTSD uncommon positive correlations between adaptation and experience of potentially traumatic event as an observer are revealed. Intrusion can be connected with a fact that at supervision learning of overcoming of a potential extreme sociogenic situation is observed. The intrusion at personality's adequate processing of the negative experiences implementing into consciousness can be potentially connected with the further adaptation to new conditions through the search of social support.

Results of the factorial analysis show that the studied selection can have the destructive ways of adaptation to new vital conditions, strengthening risks of development of PTSD. Among those: a factor of the expressed repeated traumatic experiences which are followed by problems with dream, increased irritability, fits of anger, loss of sense of reality; a factor of anxiety-uncertainty of the personality in own forces and subjective inability to self-control and to control an environment; a disadaptation factor with emotional difficulties, self-uncertainty, avoiding of communication with contemporaries concerning a problem. Generalizing the destructive factors of adaptation it is possible to note that they relate three types of disadaptation: a) strengthening of flashbacks (rexperience of last events); b) strengthening of anxiety (experience of possible future negative events); c) avoiding strengthening. Thus resources of the personality are spent for overcoming not with a real situation, but with its subjective reflection in past and future which to the same extent can't be controlled by the personality. However there are also positive factors of adaptation to an extreme sociogenic situation. Among those: a factor of strategic planning, adaptive and aimed search of an exit from a stressful situation by means of additional information, councils, sharing of feelings with others; a factor of reconsideration of own experience for the purpose of adaptation to new vital conditions. Generalizing the positive factors of adaptation, it should be noted that the transition from emotional experiences of past-future through processing and positive reconsideration of the available experience to the strategic planning of one's own life becomes critical. In this, a strengthening of an author's position of the personality, and also a proactive overcoming with a difficult life situation are shown. Gradually through understanding of borders of the influence on own life there can be PTG as a result of internal study of experiences and work on strengthening of internal and external activity.

\section{Conclusion}

This study offered a rare glimpse into how secondary trauma was manifested among Syrian adolescences resided in the refugee camp out of their native country. There has been still limited research in the field. It is revealed that in general the Syrian girls and young men, staying in a condition of hard stress disorder, show unequal symptomatology of PTSD in compliance with sexual distinctions. The Syrian young men at the stage of staying in the refugee camp have statically higher values on scales of communicative difficulties, uncertainty, nostalgia and adaptation in connection with existence of somatic frustration in digestive, respiratory, nervous systems. The girls in a smaller measure feel psychosomatic disorder in comparison with the young men. However the girls with a high level of anxiety as a personal trait show lower level of adaptation in comparison with the more emotionally stable contemporaries.

The general factorial structure of adaptation to a new situation of the compelled migration among the Syrian 
adolescence includes unproductive and productive factors of adaptation.

The unproductive factors are: 1 ) the factor of the expressed repeated traumatic experiences which are followed by problems with dream, increased irritability, fits of anger, loss of sense of reality; 2) the factor of anxiety-uncertainty of the personality in own forces and subjective inability to self-control and to control an environment; 3 ) the disadaptation factor with emotional difficulties, self-uncertainty, avoiding of communication with contemporaries concerning a problem. The productive factors of adaptation are: 1) the factor of strategic planning, adaptive and aimed search of an exit from a stressful situation by means of additional information, councils, sharing feelings with others; 2) the factor of reconsideration of own experience for the purpose of adaptation to new vital conditions.

Thus, along with the negative experiences accompanying adaptation, the resource for post-traumatic growth is observed. The last consists of prestress proactive overcoming with potential difficulties of adaptation due to understanding by the subject of the course of own crisis state. The results of this article could extend our knowledge of activity and coping strategies, especially in the context of dangerous social events.

\section{Acknowledgements}

We are grateful to the participants who gave their valuable time to take part in this study, as well as to Peoples' Friendship University of Russia for scientific and technical assistance.

\section{References}

Aspinwall, L.G., Taylor, S.E. (1997). A stitch in time: self-regulation and proactive coping. Psychological Bulletin, 121(3), 417-436.

Bajtinger, O.E. (1998). The experience of the future as a problem in early adolescence [in Russian]. Regush, L.A. (Ed). St. Petersburg: The Union, $42-50$.

Gaber Mohamed Abdallah, Greenglass, E.R. (2008). The Proactive Coping Inventory (PCI): A Multidimensional Research Instrument.

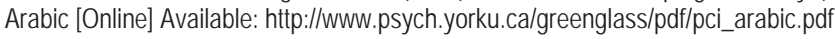

Goldstein, A.L., Wekerle, C., Tonmyr, L., Thornton, T., Waechter, R., Pereira, J., Chung, R. (2011). The Relationship Between PostTraumatic Stress Symptoms and Substance Use Among Adolescents Involved with Child Welfare: Implications for Emerging Adulthood. International Journal of Mental Health and Addiction, 9, 5, 507-524. DOI: 10.1007/s11469-011-9331-8.

Greenglass, E.R., Fiksenbaum, L. (2009). Proactive Coping, Positive Affect and Well-Being: Testing for Mediation Using Path Analysis considerations. European Psychologist, 14 (1), 29-39.

Greenglass, E.R., Schwarzer, R., Taubert, S. (1999). The Proactive Coping Inventory (PCI): A Multidimensional Research Instrument. [Online] Available: http://www.psych.yorku.ca/greenglass/pci.php;vyhledanoleden2005

Israel-Cohen, Y., Uzefovsky, F., Kashy-Rosenbaum, G., Kaplan, O. (2015) Gratitude and PTSD symptoms among Israeli youth exposed to missile attacks: examining the mediation of positive and negative affect and life satisfaction. Journal of Positive Psychology, 10, 2 (4), 99-106. DOI: 10.1016/j.jad.2015.08.038.

Johnson, S.F., Boals, A. (2015). Refining our ability to measure posttraumatic growth. Psychological Trauma: Theory, Research, Practice, and Policy, 7(5), September, 422-429.

Kochkareva, I.V. (2009). The actualization of self aspiration significance as a resource of coping behavior in difficult life situations overcoming [in Russian]. Psychopedagogy in law enforcement bodies, 3, 29-31.

Koo, K.H., Hebenstreit, C.L., Madden, E., Maguen, S. (2016). PTSD detection and symptom presentation: Racial / ethnic differences by gender among veterans with PTSD returning from Iraq and Afghanistan. Journal of Affective Disorders, 189, 1, 10-16. DOI: 10.1080/07481180500493302.

Krupnov, A.I. (2007). Psychodiagnostics of personality traits and temperament [in Russian]. Moscow: SIC MSUDT, 56 p.

Krupnov, A.I., Sheptura, A.V. (2014). Psychological differences in the manifestation of adaptability in different groups of foreign students [in Russian]. Bulletin of Peoples' Friendship University of Russia. Series: Psychology and Pedagogy, 3, 66-70.

Magomed-Jeminov, M. (2009). Posttraumatic growth phenomenon [in Russian]. Bulletin of Tambov University. Series: Humanitarian Sciences, 3, 111-117.

Magomed-Jeminov, M., Kvasova, O., Savina, O. (2015). Posttraumatic growth as a model response to the geopolitical crisis [in Russian]. Modern studies of social problems, 1 (21), 5-25.

Malyshev, I.V. (2012). Characteristics of socio-psychological adaptation and individual coping strategies in different conditions of socialization. Modern studies of social problems (Electronic Scientific Journal) [in Russian]. [Online] Available: http://cyberleninka.ru/article/n/harakteristika-sotsialno-psihologicheskoy-adaptatsii-i-koping-strategiy-lichnosti-v-raznyh-usloviyahsotsializatsii

Medvedskaya, T.S. (2010). On the problem of structural-content as well as functional personal activity components [in Russian]. Bulletin of Peoples' Friendship University of Russia. Series: Psychology and Pedagogy, 4, 84-88.

Parslow, R.A., Jorm, A.F. (2007). Pretrauma and posttrauma neurocognitive functioning and PTSD symptoms in a community sample of young adults. Psychiatry, 164, 509-515.

Pilishvili, T.S. (2014). The psychological features of youthful age personal activity [in Russian]. Moscow: RUDN, 205 p. 
Pilishvili, T.S., Al' Massri Ismaeel (2015). The features of extreme situation overcoming among syrian 15-17 years old refugees. Scientific-practical journal "Akmeology", 4 (56), 229-232.

Pilishvili, T.S., Al' Massri Ismeel (2013). The specificity of Arabic students cultural adaptation on the background of a stressful situation in the native country [in Russian]. Bulletin of Peoples' Friendship University of Russia. Series: Psychology and Pedagogy, 2, 50-55.

Salah, U., Qureshi, M.D., Long, M.E. (2011). Does PTSD Impair Cognition Beyond the Effect of Trauma? The Journal of Neuropsychiatry and Clinical Neurosciences, 23, 16-28.

Schwarzer, R. (2000). Manage stress at work through preventive and proactive coping. In E.A. Locke (Ed.), The Blackwell handbook of principles of organizational behavior, 342-355. Oxford, UK: Blackwell.

Tagay, S., Düllmann, S., Hermans, E., Repic, N., Hiller, R., Senf, W. (2011). Das Essener Trauma-Inventar für Kinder und Jugendliche (ETI-KJ). Zeitschrift für Kinder- und Jugendpsychiatrie und Psychotherapie, 39 (5), 323-340.

Tagay, S., Düllmann, S., Senf, W. (2009). The Essener Trauma-Inventar for adolescences (ETI-KJ) Essener Trauma - Inventar für Kinder und Jugendliche - Fremdbeurteilung. LVR-Klinikum Essen, Universität Duisburg - Essen. [Online] Available: https://www.uni-due.de/imperia/md/content/rke-pp/projekte/deutscheti-eti-kj_fremdbeurteilung_sept2010.pdf

Tarasova, E.V. (2010). The problem of personal aggression, self-regulation and adaptation [in Russian]. Bulletin of Peoples' Friendship University of Russia. Series: Psychology and Pedagogy, 3, 28-32.

Vodop'janova, N.E., Starchenkova, E.S. (2009). The role of resource-investment coping in extreme situations' emotional experience and the development of individual stress-resistance[in Russian]. Bulletin of St. Petersburg State University. Series 12: Series: Psychology and Social Pedagogics, 3(2), 13-22. 